\title{
A EVOLUÇÃO DA LEGISLAÇÃO AMBIENTAL NO ÂMBITO DAS ÁREAS PROTEGIDAS BRASILEIRAS
}

Bruna Letícia Thomas ${ }^{1}$

Eliane Maria Foleto ${ }^{2}$

\begin{abstract}
Resumo
O presente artigo aborda o desenvolvimento das Áreas Protegidas no país, a partir da evolução das legislações ambientais que as estabelecem. Desta forma, esta pesquisa desenvolveu-se a partir de leituras, pesquisas científicas e debates no laboratório Hidrogeo acerca da temática Áreas Protegidas e os meios legais vinculadas a ela, como o Código Florestal de 1934 e 1965, a Política Nacional do Meio Ambiente e o Sistema Nacional de Unidades de Conservação da Natureza, entre outras. Assim, percebe-se que a evolução da legislação ocorreu concomitantemente com mudanças relacionadas aos estudos ambientais, melhorando estes espaços de proteção e sua eficácia em garantir a sustentabilidade e equilíbrio ambiental. Palavras-chave: Áreas Protegidas; Legislação Ambiental.
\end{abstract}

\section{INTRODUÇÃO}

As legislações sempre foram importantes para o estabelecimento de formas de ordenamento, tanto social, econômico, territorial e ambiental. Desta forma, o Direito está diretamente vinculado aos estudos e pesquisas no âmbito das Ciências Ambientais. Uma destas formas de ordenamento é a criação de espaços de proteção ambiental. O estabelecimento destas áreas surgiu a partir dos intensos processos de ocupação e apropriação do solo e seus recursos naturais pela sociedade humana e a necessidade de criação de áreas naturais protegidas para a melhoria de qualidade de vida e geração de serviços ambientais.

Deste modo, ressalta-se que um dos mecanismos de preservação e conservação da natureza adotados no mundo todo é a criação de Áreas Protegidas. Essas são espaços territoriais protegidos por meio de legislação ambiental específica e visam à proteção e manutenção de espaços de relevância física, biológica e cultural, possuindo, portanto, a importante missão de amenizar os riscos potenciais por atividades que ameaçam a conservação da biodiversidade e manutenção do equilíbrio ambiental.

Assim, o presente artigo visa apresentar a evolução da legislação ambiental brasileira frente à criação destes espaços de proteção ambiental, visto que essa

\footnotetext{
${ }^{1}$ Geógrafa, mestranda em Geografia pelo Programa de Pós-Graduação em Geografia e Geociências da Universidade Federal de Santa Maria.

${ }^{2}$ Professora do Departamento de Geociências da Universidade Federal de Santa Maria.
} 


principalmente ao controle de uso dos recursos naturais. Entretanto, o desejo de proteção não estava considerando a importância ambiental desses, mas sim seu valor econômico, como é o caso do pau-brasil, que teve o "Regimento do Pau-Brasil", de 1605, como um instrumento de controle sobre a exploração deste recurso madeireiro (MEDEIROS, 2006).

Ainda segundo o mesmo autor, em 1797, uma Carta Régia afirmava a necessidade de conservação das matas do país, proibindo o corte não autorizado pela coroa portuguesa de espécies de árvores consideradas nobres, visto ser importante recurso para a metrópole. Contudo, apesar da adoção de alguns instrumentos visando o controle dos recursos naturais, esses ainda não podem ser considerados como Áreas Protegidas pelo fato de não haver uma demarcação de área ou território para esse fim.

Assim, por muito tempo, a proteção aos recursos ambientais no país era vista do ponto de vista econômico. A visão isolada dos atributos ambientais também foi recorrente, como pode ser exemplificada pela lei para a proteção dos recursos hídricos do país (Código das Águas de 1934) e para a proteção das florestas (Código Florestal Brasileiro de 1934): "Os recursos ambientais eram vistos de forma compartimentada e sua proteção contava com leis específicas direcionadas aos bens individualizados na natureza, ou seja, leis protetoras de flora, fauna, águas, etc.” (ARAÚJO, 2005). Ou seja, não havia a compreensão da natureza como um todo único e indissociável.

Como um marco legal inicial para as Áreas Protegidas no país, o presidente Getúlio Vargas decreta o primeiro Código Florestal Brasileiro em 1934 (Decreto Federal $n^{\circ} 23.793$ ), declarando as florestas como bens de interesse comum a todos os habitantes do país e classificando-as em quatro tipologias: protetoras, remanescentes, modelo e de rendimento.

As protetoras tinham como objetivos conservar os regimes de águas, fixar dunas, evitar a erosão, assegurar condições de salubridade pública e proteger lugares de beleza cênica. As remanescentes eram apresentadas na forma de parques nacionais, estaduais e municipais declaradas pelo poder público ou outras áreas de interesse biológico e/ou estético, sendo proibida qualquer atividade contra sua fauna e flora. Já as tipologias de floresta modelo e de rendimento eram aquelas que poderiam ser submetidas ao manejo de seus recursos, visando o extrativismo da madeira (BRASIL, 1934). 



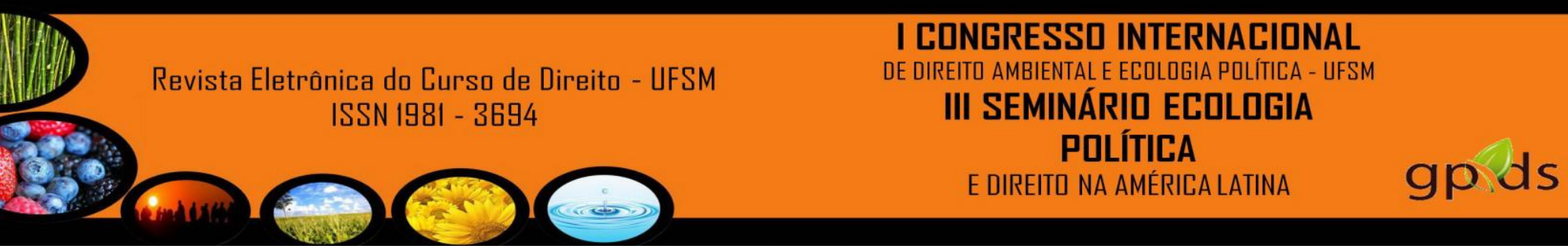

protegidos pelo poder público federal, estadual e municipal, tais como as Áreas de Proteção Ambiental, Áreas de Relevante Interesse Ecológico e Reservas Extrativistas (BRASIL, 1981). Ou seja, prevê a descentralização governamental na criação de Áreas Protegidas.

Fruto dessa política, nesse mesmo ano, é criada uma lei específica para as categorias de UC Área de Proteção Ambiental e Estação Ecológica, pela Lei Federal n ${ }^{\circ}$ 6.902, reforçando sua legitimidade. Nos anos seguintes, outras categorias também são apreciadas com suas próprias leis, como, por exemplo: Área de Relevante Interesse Ecológico (em 1984), Reserva Extrativista (em 1990) e Reserva Particular do Patrimônio Natural (em 1996).

A magna carta brasileira também passa a reconhecer a importância do meio ambiente e da necessidade de espaços de proteção. Em 1988, a nova Constituição entra em vigor no país, tendo um capítulo estabelecendo os direitos e deveres dos cidadãos brasileiros perante o meio ambiente:

Todos têm direito ao meio ambiente ecologicamente equilibrado, bem de uso comum do povo e essencial à sadia qualidade de vida, impondo-se ao Poder Público e à coletividade o dever de defendê-lo e preservá-lo para as presentes e futuras gerações (BRASIL, 1988, Art. 225).

Portanto, é dever do Estado e do cidadão a preservação dos bens naturais e o manejo adequado de ecossistemas, visando proteger a fauna, a flora, os recursos hídricos, o solo e o bem estar populacional presente e futuro. Para assegurar a efetividade desse direito, o poder público lança as bases para a criação de espaços especialmente protegidos ao apontar a necessidade de:

I - preservar e restaurar os processos ecológicos essenciais e prover o manejo ecológico das espécies e ecossistemas;

III - definir, em todas as unidades da Federação, espaços territoriais e seus componentes a serem especialmente protegidos, sendo a alteração e a supressão permitidas somente através de lei, vedada qualquer utilização que comprometa a integridade dos atributos que justifiquem sua proteção (BRASIL, 1988, p.139). 
A mesma também declara a Floresta Amazônica brasileira, a Mata Atlântica, a Serra do Mar, o Pantanal mato-grossense e a Zona Costeira como patrimônios nacionais, devendo a sua utilização garantir a preservação do meio ambiente e a perenidade dos recursos naturais (BRASIL, 1988).

Porém, mesmo havendo leis que permitiam a criação de UCs no país e, inclusive, várias já terem sido instituídas, em 2000, entrou em vigor a Lei Federal $n^{\circ}$ 9.985, que criou o Sistema Nacional de Unidades de Conservação da Natureza, o SNUC, sendo este o principal marco político na criação e gestão de UCs. Esse veio como uma forma de organizar e normatizar a criação dessas Áreas Protegidas brasileiras.

Esta lei surgiu da necessidade de amparar as UCs em forma de sistema, criando novas categorias e estabelecendo objetivos gerais e específicos de cada UC. Deste modo, em 1988 o IDBF e a SEMA (Secretaria Especial do Meio Ambiente) entraram em acordo com a ONG Fundação Pró Natureza (FUNATURA) para que esta executasse uma revisão e atualização das categorias de UCs e elaborar um anteprojeto de lei para iniciar a busca pela criação legal do sistema (PÁDUA, 2011). Assim, em 2000, o país instituiu a Lei do SNUC.

Segundo uma pesquisa das instituições/autores Ministério do Meio Ambiente, Secretaria de Biodiversidade e Florestas, Departamento de Áreas Protegidas (2007) esse sistema "consolidou uma nova atitude do Estado na relação com a sociedade no âmbito da conservação da natureza, criando uma série de mecanismos que asseguram maior participação pública no processo de criação e gestão de áreas protegidas" (MINISTÉRIO DO MEIO AMBIENTE; SECRETARIA DE BIODIVERSIDADE E FLORESTAS; DEPARTAMENTO DE ÁREAS PROTEGIDAS, 2007, p. 13). Isto é, o SNUC busca assegurar que a criação e gestão dos espaços de proteção ambiental sejam mais participativos e, deste modo, mais coerentes à dinâmica social e econômica local.

Alguns anos se passaram e as novas experiências surgidas a partir de 2000 apontaram que ainda havia necessidade de melhora. Deste modo, em 2006, visando reforçar o SNUC e o processo de criação e gestão de UCs e outras Áreas Protegidas do território brasileiro, entra em vigor o Decreto Federal $n^{\circ} 5.758$, que institui o Plano Estratégico Nacional de Áreas Protegidas, o PNAP. Este vem como resultado de um 
III SEMINÁRII ECOLOGIA

PDLÍTICA

compromisso assumido pelo país ao assinar a Convenção sobre Diversidade Biológica durante a Conferência das Nações Unidas sobre Meio Ambiente e Desenvolvimento (CNUMAD) de 1992, onde se visa estabelecer um sistema abrangente de Áreas Protegidas, ecologicamente representativo e efetivamente planejado, integrando paisagens terrestres e marinhas mais amplas até o ano de 2015 (BRASIL, 2006).

Dentre as novas contribuições do PNAP às Áreas Protegidas brasileiras está o reconhecimento destas como um dos instrumentos eficazes para a conservação, não só da diversidade biológica, mas também sociocultural. Quilombolas, camponeses e caiçaras são atores muito importantes na conservação ambiental no país ao trabalhar de forma sustentável em suas pequenas propriedades, situadas nos diversos biomas brasileiros.

Além disso, os princípios deste decreto visam solucionar os problemas encontrados em muitas Áreas Protegidas e que não foram solucionados pelo SNUC: a necessidade de sustentabilidade técnica e financeira para assegurar a continuidade de gestão e a importância na consolidação territorial das UCs e demais Áreas Protegidas.

Assim como o SNUC, o PNAP também dá importância à necessidade de uma abordagem ecossistêmica no estabelecimento de deste espaços, dando destaque às terras indígenas e quilombolas:

O PNAP reconhece a importância das terras indígenas e das terras de comunidades remanescentes de quilombos como parte da política de conservação da biodiversidade brasileira. Ao integrá-las ao esforço de planejamento da paisagem, ao lado das UCs, o PNAP amplia de forma inovadora a abordagem ecossistêmica dada à política nacional, contemplando ainda as Áreas de Preservação Permanente e Reservas Legais como elementos de conectividade entre fragmentos naturais e as próprias Áreas Protegidas (MINISTÉRIO DO MEIO AMBIENTE; SECRETARIA DE BIODIVERSIDADE E FLORESTAS; DEPARTAMENTO DE ÁREAS PROTEGIDAS, 2007, p. 26 e 27).

Ou seja, o PNAP vem de acordo com a nova visão acerca da criação de espaços de proteção, que devem analisar a paisagem como um todo, e não mais de forma isolada. Atualmente, visa-se a interação com os atributos e paisagens ambientais do 



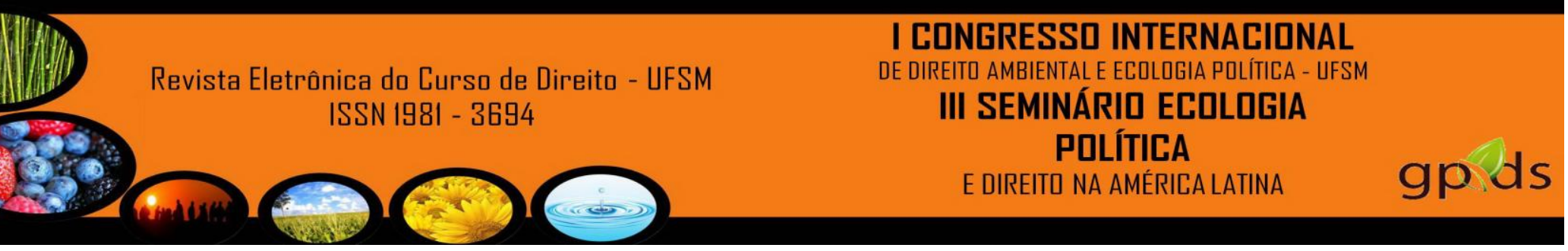

ambiental; as formas de proteção isoladas e compartimentadas para uma proteção integradora e sistêmica; a agregação da questão indígena e a proteção dos aspectos socioculturais; o estabelecimento de Unidades de Conservação; a descentralização governamental no processo de criação destas áreas; entre outras.

Vale destacar que as Áreas Protegidas não são resguardadas legalmente por acaso: estas áreas são ambientalmente importantes pois sua estrutura, dinâmica e função contribuem para a manutenção da qualidade de vida das populações e, desta forma, necessitam de regramentos específicos para garantir sua proteção e evitar sua degradação.

\section{REFERÊNCIAS}

ARAÚJO, L. A. de A. Perícia ambiental. In: CUNHA, S. B. da; GUERRA, A. J. T (Org.). A questão ambiental: diferentes abordagens. 2 ed. Rio de Janeiro: Bertrand Brasil, 2005, p. $107-152$.

BENSUSAN, N. Conservação da biodiversidade em áreas protegidas. Rio de Janeiro: FGV, 2006.

BRASIL. Decreto Federal n. 23.793, de 23 de janeiro de 1934. Aprova o código florestal que com este baixa. Presidência da República - Subchefia para Assuntos Jurídicos, Rio de Janeiro, RJ, 23 jan. 1934. Disponível em: < http://www.planalto.gov.br/ccivil_03/decreto/1930-1949/d23793.htm>. Acesso em: 26 jan 2012.

Lei Federal n. 4.771, de 15 de setembro de 1965. Institui o novo Código Florestal. Presidência da República - Casa Civil, Brasília, DF, 15 set. 1965. Disponível em: <http://www.planalto.gov.br/ccivil_03/Leis/L4771.htm>. Acesso em: 29 maio. 2011.

Lei Federal n. 6.902, de 27 de abril de 1981. Dispõe sobre a criação de Estações Ecológicas, Áreas de Proteção Ambiental e dá outras providências. Presidência da República - Subchefia de Assuntos Jurídicos, Brasília, DF, 27 abr. 1981. Disponível em: < http://www.planalto.gov.br/ccivil_03/leis/L6902.htm>. Acesso em: 26 jan. 2012.

Lei Federal n. 6.938, de 31 de agosto de 1981. Dispõe sobre a Política Nacional do Meio Ambiente, seus fins e mecanismos de formulação e aplicação, e dá outras 


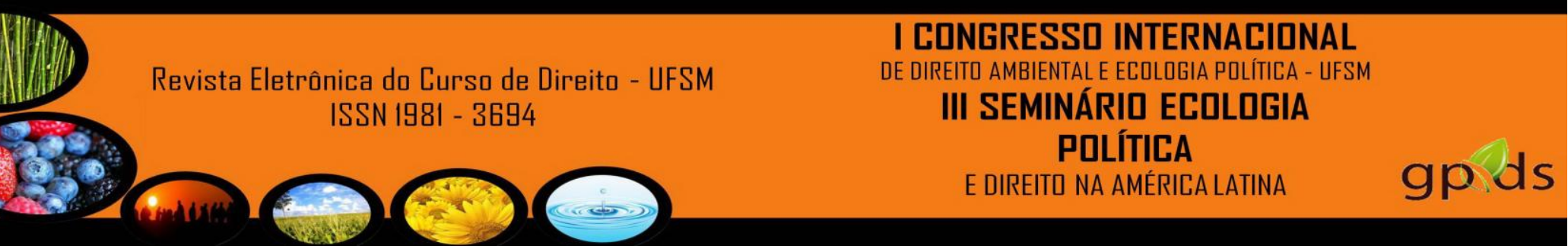

providências. Presidência da República - Casa Civil, Brasília, DF, 31 ago. 1981. Disponível em: <http://www.planalto.gov.br/ccivil_03/Leis/L6938.htm>. Acesso em: 11 maio 2011.

Constituição (1988). Constituição da República Federativa do Brasil: promulgada em 5 de outubro de 1988: atualizada até a Emenda Constitucional n. 39, de 19-12-2002. 31 ed. São Paulo: Saraiva, 2003, 364 p.

Lei Federal n. 9.985, de 18 de julho de 2000. Regulamenta o art. 225, $\S 1^{\text {o }}$, incisos I, II, III e VII da Constituição Federal, institui o Sistema Nacional de Unidades de Conservação da Natureza e dá outras providências. Presidência da República Casa Civil, Brasília, DF, 18 jul. 2000. Disponível em: <http://www.planalto.gov.br/ccivil_03/leis/19985.htm>. Acesso em: 29 maio 2010.

Decreto Federal n. 5.758, de 13 de abril de 2006.

Institui o Plano Estratégico Nacional de Áreas Protegidas - PNAP, seus princípios, diretrizes, objetivos e estratégias, e dá outras providências. Presidência da República Subchefia para Assuntos Jurídicos, Brasília, DF, 13 abr. 2006. Disponível em: < http://www.planalto.gov.br/ccivil_03/_Ato2004-2006/2006/Decreto/D5758.htm>.

Acesso em 18 jan. 2012.

DRUMMOND, J. A.; FRANCO, J. L. de A.; NINIS, A. B. O estado das áreas protegidas do Brasil - 2005. Brasília: [s.n.], 2006.

MEDEIROS, R. Evolução das tipologias e categorias de Áreas Protegidas no Brasil. Ambiente \& Sociedade, Campinas, n. 1, jan./jun., 2006, p. 41-64. Disponível em: <http://www.scielo.br/pdf/asoc/v9n1/a03v9n1.pdf>. Acesso em: 17 abr. 2011.

MEDEIROS, R.; YOUNG, C. E. F. Contribuição das unidades de conservação brasileiras para a economia nacional: Relatório Final. Brasília: UNEP-WCMC, 120 p. Disponível em: <http://www.mma.gov.br/estruturas/sbf2008_dap/_publicacao/149_publicacao0806201 1100539.pdf >. Acesso em: 01 jun. 2011.

MINISTÉRIO DO MEIO AMBIENTE, SECRETARIA DE BIODIVERSIDADE E FLORESTAS, DEPARTAMENTO DE ÁREAS PROTEGIDAS. Informe nacional sobre áreas protegidas no Brasil. Brasília: MMA, 2007.

PÁDUA, M. T. J. Do Sistema Nacional de Unidades de Conservação In: MEDEIROS, R.; ARAÚJO, F. F. S. (Org.). Dez anos do Sistema Nacional de Unidades de 


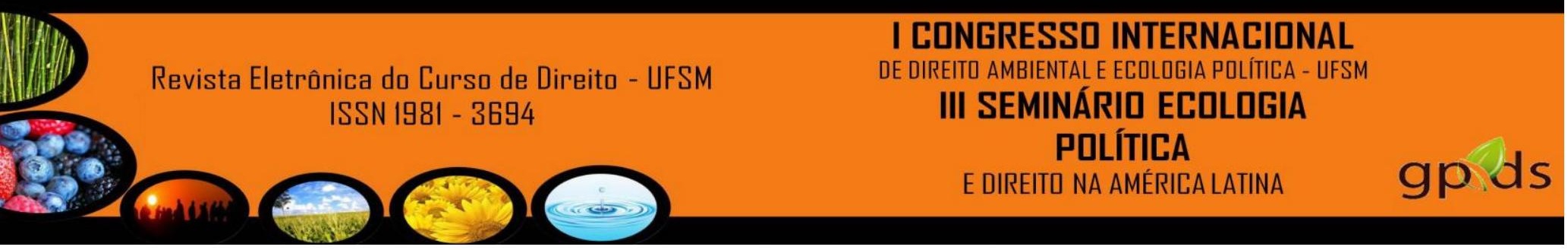

Conservação da Natureza: lições do passado, realizações presentes e perspectivas para o futuro. Brasília: MMA, 2011, p. 21 - 35.

SCHERL, L. M., et al. As áreas protegidas podem contribuir para a redução da pobreza? Oportunidades e limitações. Reino Unido: IUCN, 2006. 